\section{THE TEACHING OF CHEMICAL PRINCIPLES}

CECTIONS B (Chemistry) and L (Education) of $D$ the British Association held a joint discussion on September 6 on "The Teaching of Chemical Principles in School and University". In connexion with this discussion an exhibition of teaching models and demonstrations was arranged by the Chemistry Departments of the University of Bristol.

Opening the discussion, Prof. D. H. Everett (Bristol) said that in the past twenty or thirty years teachers of chemistry have been faced with new problems reminiscent of those raised at the end of the past century by the advent of physical chemistry. There is, he said, less need now to emphasize the principle that the physical basis of chemistry should form a framework for the teaching of chemistry; instead, the more important questions are concerned with the stage at which modern theoretical ideasquantization of energy and of radiation; wave mechanics; atomic and molecular orbitals ; statistical mechanics and thermodynamics - should be introduced, and with the way in which the abstractions with which they deal can be explained to the uninitiated.

The usual university honours course in chemistry has long since ceased to deal with more than a very small fraction of the total extent of chemical knowledge. However, specialization at an early stage in an honours course, with the object of achieving a detailed coverage of a small part of the subject, is undesirable in itself and obscures from the student the power of the underlying principles to unify the subject. It seems more than ever important that chemical education should not only provide the student with a basic knowledge of the facts of chemistry, but should also develop in him an intuition which will enable him to appreciate the significance of new facts as he meets them. It was argued that there should be a place in the univensity curriculum for a course in chemical principles which would acquaint the student with the more important features of a wide range of phenomena, and which would show how these are linked by fundamental theory. (An extended essay on this theme is to be found in "The Structure of Physical Chemistry", by Sir Cyril Hinshelwood: the treatment in this book is, however, on a more advanced plane than that foreseen by Prof. Everett.) Some more highly specialized topics would be crowded out of the undergraduate into the postgraduate curriculum, but this is not a serious disadvantage. The understanding derived from a course of this kind is more important than an encyclopædic knowledge of chemical facts.

The physical concepts upon which the principles of chemistry are based are nearly all abstract in nature. The ability to appreciate abstract thought develops slowly, and there are in consequence two opposing views concerning the method of introduction of these ideas. Either they should be deferred until the student is more mature, or they may be introduced early in the university course so that he may have time to understand their value by the end of the course. Because of mathematical difficulties, it is impossible to give a rigorous discussion, and so we must be satisfied with" an introductory treatment based on models and analogies, which gives a partial understanding. All such simplifications are, however, half-truths, which if applied incautiously can lead to confusion; but if the models and analogies are carefully chosen, and presented with the right emphasis, the dangers of the 'simple introduction' can be minimized. Some ideas implanted in an early course may have to be rejected later, but the student must be prepared to develop his ideas throughout his training: this evolutionary process is characteristic of the development of science as a whole, and a realization of this fact is important to the student.

Prof. Everett expressed the opinion that many of the fundamental ideas can be explained to students at an early stage in their course (Inter. B.Sc. or firstyear degree course) by means of simple mechanical models designed to illustrate macroscopic analogies of the molecular situation rather than to represent the actual atomic or molecular state of affairs. $\mathrm{He}$ then demonstrated a series of models illustrating, among other things, the quantization of orbits in the hydrogen atom; absorption and emission of energy in definite quanta; the development of the periodic system of elements in terms of the electronic energylevels; atomic orbitals; molecular orbitals; the free-energy relationships in an allotropic change, and in the solution of a solid in a liquid. More detailed descriptions of these models will be published in the Advancement of Science.

Prof. C. A. Coulson (Oxford) read a paper on the "Teaching of Quantum Mechanics to Chemists". He said that no greater change in chemical understanding has ever taken place in modern times than that associated with the advent of quantum mechanics. As a result, to-day no chemical education is worth considering which fails to take account of this development. Yet quantum theory itself is too wide, and too complicated, to present to chemistry students at a university. For practical purposes it seems as if wave mechanics must bear the effective emphasis. This is, by comparison with other forms of quantum theory, relatively simple, and makes more use of conventional ideas such as probability.

Wave mechanies in chemistry is based on two concepts : the idea of quantization, and the description of electron properties. Neither of these is likely to be obvious, despite the efforts of the popular Press. Hence we seek some simple analogy, or model. These analogies and models seem to be of first-rate importance, since without them there is little or no chance that the student will acquire a 'feel' for these modern interpretations. But they are dangerous, and have often led to serious confusion.

Quantization can be approached via the de Broglie relation and the familiar example of standing waves in a violin string. Electron properties--for the chemist-resolve themselves chiefly into probability distributions (or, more simply, the idea of a chargecloud) and spin. In the first of these the most important factor to stress is shape. It is unimportant in earlier stages to relate these to magnetic properties. There seems no simple model or analogy for electron spin, and all attempts to provide one seem doomed to cause great confusion later. (Physicists may be able to understand the vector model of an atom, etc., but it is doubtful if chemists should be expected to do so.) A simple version of the Pauli exclusion principle is easily written down, adequate to deal with most ground-states of atoms and molecules, and Hund's rules for incomplete shells can be stated plausibly.

Prof. Coulson expressed the view that every chemist should have some familiarity with wave functions, and suggested that the two lowest-energy 
states of the hydrogen atom could be worked out by students-this would give confidence that more complete treatments for more complex systems would in fact yield the correct answer.

As an example of the dangers in all elementary accounts, Prof. Coulson cited the frequent misuse of the word 'resonance'. A critique of this concept should be regarded as part of any course on wave mechanics, and leads easily and naturally to a discussion of the true status of wave mechanics, as a most valuable conceptual tool, which gives insight into chemical phenomena, but which is severely limited if accurate $a b$ initio calculations are desired. No electronic computer will replace a chemical laboratory.

The third main paper was read by Mr. G. I. Brown (Eton), who gave as the duty of a science master that of understanding the developments in science and interpreting and presenting them in a simplified form to the uninitiated. He considered it important that there should be no undue delay in incorporating new advances into school teaching. This is no easy task for the teacher, and Mr. Brown urged more liaison between active teachers in universities and schools. $\mathrm{He}$ welcomed tho opportunity for this discussion, also, because it provided a chance of emphasizing the attractions of a teaching career. The teaching of chemistry can be made both interesting and attractive by the variety of possible ways of presenting it, and by the different requirements of students. He stressed that the advanced course of chemistry at school must never be a narrow one, but should give some indication of the importance of all the aspects of chemistry. Each teacher must to some extent decide on the type of approach to be adopted. However, the recent trend towards an undue emphasis on the social and economic aspect was deprecated as one which can too easily give the impression that chemistry is solely concerned with such things as nylon underwear.

Mr. Brown considered that the basis of the course for sixth-form science students should be a theoretical one, involving a study of fundamental chemical principles. Of these the most useful as a unifying framework is modern valency theory. Chemistry is often criticized as a school subject on the grounds that it can be learnt simply by perseverance and hard work, and that it involves too little real thinking. It is true that, below sixth-form level, chemistry cannot fail to be largely a matter of routine learning of apparently unconnected facts-but young boys make no objection to learning the facts, and many have little difficulty in doing so. What is difficult, at this stage, is to exercise the mind of the student in the same way as it is exercised in the learning of, say, mathematics or Latin. There comes a time, usually while still at school, when a boy begins to ask more fundamental questions-and then his mind must be stimulated by something more than a mere catalogue. Mr. Brown expressed his belief that modern valency theory provides the necessary interest, and that despite the criticisms levelled against its introduction in school-teaching, the benefits derived from its use far outweigh the reduction in factual knowledge implied by a change in the balance of study.

Mr. Brown was critical of examining bodies who continue to set questions requiring for their answer the recollection of far too many unimportant facts, and pointed out that the quickest and most effective way of changing the character of school-teaching is to change examination syllabuses and the nature of the examination questions.

The two main contributors to the general discussion which followed were Mr. J. C. Stredder (Tonbridge) and Mr. A. C. Cavell (Uppingham). Mr. Stredder, while not rejecting the incorporation of more recent theories in teaching at school, stressed the dangers of such a policy. He was particularly concerned that an inexperienced pupil, who is unable to criticize-and perhaps unable to understand-the experimental evidence on which modern theories are based, must either allow his critical faculty to be dulled, or must accept such theories as fairy-tales in which he may one day believe. There is a danger that not only facts but also theories will be learned parrot-fashion. Furthermore, the introduction of many modern ideas must depend on the pupil having a sufficient background in physics; and often this cannot be provided adequately at school. Mr. Stredder was of the opinion that, with some exceptions, boys are scarcely ready to be introduced to subjects such as the wave nature of the electron, atomic orbitals, resonance and molecular orbitals until they enter a university.

Mr. Cavell was anxious that developments in chemistry teaching in schools should take account of the educational as well as the more specialized technical aspects. He expressed the view that both schools and universities are attempting to teach too wide a syllabus in science, and that by introducing too much detail, insufficient time is available for dealing with basic principles. While agreeing with Mr. Brown that modern valency theory helps to make sense of chemistry, and encourages thought and discussion, Mr. Cavell said that in his experience the evidence provided by school certificate scripts suggests that either this approach is not being widely used, or that candidates are averse to using it in answering examination questions. His agreement with Prof. Everett, that a rational rather than a strictly historical approach is to be preferred, was qualified by the view that one of the fundamental educational weaknesses of science is that it deals more with things than with people. Consequently, he argued, no opportunity should be lost of introducing historical and biographical detail in an attempt to humanize the subject. Mr. Cavell also appoaled for eloser co-operation between teachers in school and university, especially in connexion with the revision of school syllabuses, the provision of courses for science teachers at universities, and on detailed techniques of science teaching.

\section{PROPERTIES AND DISTRIBUTION PROBLEMS OF RAW COTTON}
A
ONE-DAY conference on "Raw Cotton, its Properties and Distribution", arranged by the Manchester and District Section of the Textile Institute, was held in Liverpool on November 23 to facilitate the participation of raw-cotton merchants in discussing current problems in the growing and maxketing of raw cotton with the spinning and weaving sides of the cotton industry. It was also hoped that the conference would illustrate part of the wide field of activities undertaken by the Textile Institute and so encourage the formation of a Liver- pool section. Four papers were presented for con- 